\title{
Filosofia, tom e ilusão musical em Kant. DA VIVIFICAÇÃO SONORA DO ÂNIMO À RECEPÇÃO DO TOM DA RAZÃO ${ }^{1}$
}

\author{
Nuria Sánchez Madrid²
}

A voz humana pode ser abstrata, ser, possivelmente, a abstração do homem. Mas isso seria uma espécie de abstração parecida com a do corpo desnudado. Já é quase um pudendum! (T. Mann, Doutor Fausto).

RESUMO: O artigo tenciona, primeiramente, enriquecer o estudo da função que o conceito de tom desempenha na ideia kantiana de razão, ao estendê-lo à análise da música como arte dos sons que a Crítica do Juíro contém. Em segundo lugar, propõe-se determinar os motivos pelos quais a matemática se revela incapaz, devido à especificidade do método filosófico e à corporalidade da recepção musical, respectivamente, de expressar o modo de proceder da razão e da arte dos sons. Finalmente, aponta-se para uma semelhança entre música e razão, no que diz respeito à rejeição que compartilham da queda na Schwärmerei, apesar da distância que se estabelece entre ambas enquanto duas maneiras contrárias de exercitar e fomentar a vida e o sentimento dela.

PALAVRAS-CHAVE: Crítica. Razão. Tom. Música. Matemática. Espécie de adesão. Sentimento vital.

\footnotetext{
${ }^{1}$ Este artigo resulta da pesquisa realizada no âmbito do Projeto de Pesquisa Naturaleza bumana y comunidad (II): H. Arendt, K. Polanyi y M. Foucault. Tres recepciones de la Antropología política de Kant en el siglo XX (FFI2009-12402), apoiado pelo MICINN do Governo de Espanha. Agradeço às prezadas observações que o prof. Ubirajara Rancan de Azevedo Marques (UNESP) me comunicou sobre uma versão anterior do artigo. A conferência "Kant e as metáforas musicais", ministrada pelo prof. Ubirajara R. de Azevedo Marques, na Faculdade de Filosofia da Universidade Complutense de Madrid, no dia 12 de julho de 2011, contribuiu para demarcar os objetivos do presente trabalho.

2 Nuria Sánchez Madrid é professora da Faculdade de Filosofia da Universidade Complutense de Madrid, onde ministra cursos principalmente nas áreas de ontologia, metafísica e filosofia da ação. Publicou artigos sobre o uso da teleologia e a antropologia política de Kant, nas revistas Daimon, Themata, Logos e Kant e-prints, além de participar nas Atas de vários Congressos internacionais centrados em Kant. Recentemente, traduziu para o espanhol o escrito Primeira introdução à Crítica do Juíro de I. Kant (Madrid: Escolar y Mayo, 2011). É membro do Grupo de Pesquisa da UCM "Metafísica, Crítica y Política”. E-mail: nuriasma@filos.ucm.es.
} 
A Crítica de Kant não é em absoluto indiferente ao tom usado no campo da filosofia, especialmente quando se tratar de discussões de natureza polêmica relativas aos objetos principais da traditio metafísica. $\mathrm{Na}$ Crítica da razão pura, podese ler que nesse tipo de discussões “[o] que está [...] em litígio não é a coisa mas o tom”, pois, às vezes, após descobrir a impotência cognoscitiva sobre certos objetos, a renúncia à ciência mostra como o avesso da certeza a emergência duma "fé sólida" que a razão não só aceita, mas promove, devido ao fato de a sua própria existência depender da consolidação desse modo de adesão. Por sua vez, com respeito à prova físico-teológica da existência de Deus, Kant põe de sobreaviso os efeitos prejudiciais duma fingida redução da "[...] linguagem dogmática de um sofista arrogante ao tom de reserva a de moderação conveniente a uma fé" 5 , pois precisamente o dogmatismo ignora o alcance do tom em filosofia, ao não se interessar pela diferença entre as espécies de adesão [Fürwabrbalten $]^{6}$ das faculdades de conhecer aos objetos de conhecimento, quer dizer, por descuidar da pergunta pelos limites e não considerar o uso legítimo dessas faculdades. Uma operação semelhante acontece ao aconselhar-se que "[...] o orgulhoso nome de ontologia" se veja substituído "[...] pela mais modesta denominação de simples analítica do entendimento", mais atenta aos limites do uso e sentido dos princípios transcendentais do entendimento puro. Outra referência preliminar tocante ao rasto tonal do uso da razão levar-nos-ia ao desprezo mostrado no próprio tempo da Crítica em face da outrora considerada rainha das ciências, ou seja, a Metafísica, tornada uma quérula e plangente Hécuba por obra do "tom de moda" [Modeton $]^{8}$ da época na qual eclode um juízo amadurecido. A mesma presunção dos indiferentistas quanto às questões metafísicas, ao preferir o tom

\footnotetext{
${ }^{3} \mathrm{KrV}$, A disciplina da razão pura relativamente ao seu uso polêmico, A 744/B 772. As obras de Kant são citadas a partir da edição da Akademie e de acordo com o padrão definido pela Kant-Forschungsstelle (http://www.kant.uni.mainz.de).

${ }^{4}$ Ibid.

${ }^{5} \mathrm{KrV}$, A 624/B 652, grifo nosso.

6 KU, \91, AA V: 454: "Se considerarmos simplesmente o modo como algo pode ser para nós (segundo a constituição subjetiva das nossas faculdades de representação) objeto de conhecimento (res cognoscibilis), compararemos então os conceitos, não com os objetos, mas sim simplesmente com as nossas faculdades de conhecimento e com o uso que estas podem fazer da representação dada (numa intenção teórica ou prática). A questão de saber se algo é ou não um ser suscetível de conhecimento não diz respeito à possibilidade das próprias coisas, mas sim do nosso conhecimento das mesmas".

${ }^{7} \mathrm{KrV}, \mathrm{A} 247 / \mathrm{B} 303$, grifo nosso.

${ }^{8} \mathrm{KrV}$, A VIII-A IX. Tradução ligeiramente modificada.
} 
popular [populären Ton $]^{9}$ à terminologia monopolizada pelas escolas ${ }^{10}$, não pode se eximir de precisar do vocabulário e de estruturas metafísicas, desde que eles tencionem simplesmente pensar.

A partir das citações precedentes, poderíamos extrair a impressão de a atividade do pensamento se ver sempre acompanhada dum tom ou som [Ton], duma Stimmung das faculdades do ânimo — poderíamos acrescentar —, apenas reconhecível para o exercício da crítica, que substitui a avaliação de livros e sistemas pelo estudo dos princípios e do alcance da razão em geral ${ }^{11}$. Assim, Kant pode fazer alusão aos riscos que o desejável "espírito de profundeza" correu na Alemanha, por obra do tom de moda "[...] de uma liberdade de pensar com foros de genial"12, a que ele redarguirá com rigor no escrito titulado Dum tom enaltecido recentemente percebido na filosofia [Von einem neuerdings erhobenen vornehmen Ton in der Philosophie]. Nesse contexto, Kant previne dos prejuízos resultantes da combinação entre a curiosidade alastrada, especialmente entre os jovens, pelo tom de moda na época com os resultados de uma educação segundo um método dogmático, pois se trata, nos dois casos, de aproximações superficiais ao exercício do pensamento. Do encontro entre o tom de moda dos mais novos e aquele orgulhoso dos dogmáticos apenas é pensável esperar que a “[...] vantagem da novidade” chegue a abater os segundos, devido à manifesta incapacidade que eles têm para descobrir "[...] a dialética oculta que se encontra no seio [do filósofo dogmático] como no do antagonista" ${ }^{13}$. O primeiro disfarça essa carência de censura e repressão, de modo que a polêmica filosófica se reduzirá a uma competição dos mais novos frente aos que se tornaram antiquados, quer dizer, a um simples combate de divisas mais ou menos sutis, que decorre entre correntes e modas e do qual a razão estará completamente ausente.

Forma parte da hermenêutica filosófica kantiana, do projeto duma philosophirende Geschichte der Philosophie, ensaiada nos Progressos da Metafísica dos tempos de Leibniz e Wolff (1793), também esclarecida pelo próprio Kant, na mesma obra, como uma arqueologia filosófica, colocar os fundamentos racionais das afirmações metafísicas, além das conjunturas empíricas e cronológicas ${ }^{14}$. Tal

\footnotetext{
${ }^{9} \mathrm{KrV}, \mathrm{A} \mathrm{X}$.

${ }^{10} \mathrm{Na} \mathrm{KrV}$ (B XXXII), faz-se alusão ao "Monopol der Schulen", que manifesta desprezo pelo "Interesse der Menschen".

${ }^{11} \mathrm{KrV}$, A XII.

${ }^{12} \mathrm{KrV}$, B XLIII. Trad. ligeiramente modificada.

${ }^{13} \mathrm{KrV}, \mathrm{A} 754 / \mathrm{B} 782-\mathrm{A} 755 / \mathrm{B} 783$.

${ }^{14}$ Vd. RIBEIRO DOS SANTOS, L. (1994, p. 174): "Kant é levado a problematizar a própria historicidade da razão e a esboçar os fundamentos de uma «história filosófica da filosofia". Por breves
} 
história da filosofia não se podia manter alheia à estreita relação entre a atividade do pensamento e o uso da linguagem. Sendo verdade que os pensamentos só se encarnam nas palavras e sintagmas linguísticos, não despertará estranheza o fato de ser possível descobrir na linguagem que uns e outros filósofos usam tons diferentes, não todos condizentes aos propósitos da Aufklärung. Com efeito, nós, os homens, pensamos apenas "[...] mediante os signos" [durch die Zeichen] $]^{15}$, quer dizer, in abstracto, sem esquecer que as palavras são uma espécie de custódio [Wachter; custos $]^{16}$ dos conceitos, não signos da construção in concreto deles. Sendo esta a dependência da razão com respeito à linguagem, é preciso sublinhar a profundidade subjetiva do ato linguístico de pensar:

Toda língua é designação de pensamentos e, inversamente, a forma mais primorosa de designar pensamentos é pela língua, esse meio soberano de entender a si mesmo e aos outros. Pensar é falar consigo mesmo (os índios de Otaheite chamam o pensar de linguagem do ventre), por conseguinte, também de ouvir interiormente (por meio da imaginação reprodutiva). Para o surdo de nascimento seu falar é um sentimento de jogo de seus lábios, língua e maxilar, e quase não é possível pensar que em sua fala ele faça algo mais que jogar com sentimentos corporais, sem ter conceitos próprios nem pensar. ${ }^{17}$

Atente-se para a diferenciação no trecho entre um jogo com sentimentos corporais, atribuída aos surdos de nascimento, e o pensar por meio de conceitos, pois essa dupla se tornará interessante quando abordarmos mais de perto dos efeitos da música sobre o ânimo humano. De momento, bastará enxergar o fato de que há uma única linguagem autêntica, sem prejuízo da variedade empírica delas, mas também linguagens análogas com a primeira, como a linguagem dos surdos. Restaria por analisar se a linguagem (musical) das afecções corre idêntica sorte. É uma constante kantiana salientar que o filósofo sempre pensa em companhia de outros, isto é, com ajuda doutros indivíduos, que contribuirão para corrigir e aprimorar o seu

que sejam as indicações dadas nesse sentido, elas não deixam de constituir uma autêntica "revolução coperniciana" no modo de encarar a "história da filosofia", a qual passa a ser vista não como "[...] história das opiniões que aparecem aqui ou ali, mas como história da razão que se desenvolve a partir de conceitos" e onde a ordem cronológica da sucessão dos três estádios (dogmatismo, cepticismo, criticismo) "[...] se funda na natureza da humana faculdade de conhecer" (cf. p. 133; 19). Beneficioume muito sobre a maneira kantiana de confrontar a história da filosofia a leitura do trabalho de Rodrigo Andia (2007).

15 Vd. Untersuchung, AA 02: 278.

16 АpH, AA 07: 191.

$17 \mathrm{ApH}, \mathbb{\int} 39, \mathrm{AA} \mathrm{07:192.}$ 
pensamento $^{18}$. No âmbito dessa comunidade de pensamento, será interessante levar em conta a copresença de tons e afecções correspondentes às palavras. Quando Kant pede ao interlocutor para receber, como "pobre filho da terra" as opiniões dele "[...] se possível, na linguagem dos homens"19, está reivindicando o meio linguístico como o único capaz de conduzir aos homens a consensos não artificiais nem indignos dum ser provido de razão. A mesma manutenção da palavra dada [Worthaltung] é sinal do amor da verdade [Wabrheitsliebe] dos falantes ${ }^{20}$, porquanto a palavra é a expressão e custódio do conteúdo verdadeiro. Por isso, ela deve ser especialmente protegida pela comunidade filosófica, conforme os interesses e fins da humanidade. Estudiosos da obra de Kant, como Chiara Fabbrizi, encontram na ideia kantiana da linguagem um considerável progresso com respeito a teorias que pretendem esclarecer a atividade do pensamento por meio do recurso às ideae materiales, de sólida tradição entre os cartesianos:

Kant substitui por meio da linguagem o sistema fisiológico das ideae materiales, sistema altamente dogmático, pois nenhum componente fisiológico se pode identificar cientificamente com a alma. ${ }^{21}$

Após marcar a onipresença, por vezes implícita e oculta, da linguagem na análise kantiana da razão, proporíamos dirigir a atenção à pertença à linguagem duma das belas artes de funcionamento mais enigmático, quer dizer, a música. Da mesma maneira que a razão permite reconhecer o tom que aguarda debaixo das afirmações dela, a música será considerada por Kant como uma arte dos sons [Tonkunst], sem, porém, mostrar ulteriores semelhanças entre elas além da mútua ligação ao campo do som, sobre o qual parecem abrir perspectivas tão enfrentadas quanto complementares. Quando Kant se detém, na terceira Crítica, no estabelecimento de uma hierarquia das belas artes, recorre a uma analogia com a língua. No $\int 51$ da Crítica do Juízo Kant escolhe — frisando em todo momento que se trata de uma experiência e não de uma verdadeira teoria — as três ordens reconhecíveis na linguagem como fio condutor duma exposição das belas artes:

\footnotetext{
${ }^{18} \mathrm{Vd}$. WhDo?, AA 08: “[Q]uanto e com que correção pensaríamos nós se, por assim dizer, não pensássemos em comunhão com os outros, aos quais comunicamos os nossos pensamentos e eles nos comunicam os seus! Pode, pois, muito bem dizer-se que o poder exterior, que arrebata aos homens a liberdade de comunicar publicamente os seus pensamentos, lhes rouba também a liberdade de pensar: o único tesouro que, não obstante todos os encargos civis, ainda nos resta e pelo qual apenas se pode criar um meio contra todos os males desta situação".

19 Vd. Carta de Kant a Hamman, AA 10: 194.

$20 V$ d. Observaçoes sobre o sentimento do belo e do sublime, AA 20: 153.

${ }^{21}$ Vd. (2008, p. 229). Cf. L. RIBEIRO DOS SANTOS, 1994, p. 39-67.
} 
[S]e queremos dividir as belas-artes, não podemos pelo menos como tentativa escolher para isso nenhum princípio mais cômodo do que o da analogia da arte com o modo de expressão, da qual os homens se servem no falar para se comunicarem entre si tão perfeitamente quanto possível, isto é não simplesmente segundo conceitos mas também segundo as suas sensações. -Este modo de expressão consiste na palavra, no gesto, e no tom (articulação, gesticulação e modulação). Somente a ligação destes três modos de expressão constitui a comunicação completa do falante. Pois pensamento, intuição e sensação são simultânea e unificadamente transmitidos aos outros. ${ }^{22}$

Uma divisão dicotômica das artes, à qual Kant se refere também um pouco mais à frente, baseada na capacidade delas para exprimir conteúdos conceptuais ou intuitivos, teria trazido consigo uma impressão artificiosa, que bastaria conferir com a força hermenêutica do uso da linguagem para preferir a eleição inicial. Nesse contexto, a Crítica reserva um ambíguo espaço para a música, sem dúvida tão próxima à matemática por tradição quanto incômoda para o desenvolvimento das operações do pensamento. O $\ 53$ da mesma obra refere-nos a um falar "[...] por meras sensações, sem conceitos" ${ }^{\prime 2}$, que, ainda não ofereça nada relevante para reflexionar, tem a qualidade de mover "[...] o ânimo do modo mais variado e, embora só passageiramente, no entanto mais intimamente"24. Essa capacidade de comoção animica ${ }^{25}$ eleva a música às posições mais elevadas da hierarquia estética, mas unicamente do ponto de vista do gozo, porque a razão abriga firmes prevenções contra a influência que essa arte mostra ter no ânimo. Se quisermos esclarecer um pouco mais esse primeiro aspecto da música, teríamos que atentar para o fato de que o atrativo [Reiø] associado a ela está ligado à interconexão de

\footnotetext{
$22 K U, \int 51$, AA 05: 320.

${ }^{23} \mathrm{KU}, \mathbb{\Omega} 53, \mathrm{AA} 05: 328$.

${ }^{24}$ Ibid, grifo nosso.
}

${ }^{25}$ Geralmente, esse efeito da música é considerado como o avesso da harmonia, quer dizer, como efeito da melodia, que, por exemplo, o Hegel da Estética estima, numa linha interpretativa que se remonta a Rousseau, como a dimensão principal duma peça musical: "A harmonia, a saber, abrange apenas as relações essenciais que constituem a lei da necessidade para o mundo dos sons, mas tampouco como o compasso e o ritmo ela abrange a música propriamente dita, e sim apenas a base substancial, que são o fundamento e o terreno regulares sobre os quais se move a alma livre. O poético da música, a linguagem da alma, que derrama o prazer interior e a dor do ânimo em sons e nesta efusão se eleva suavemente acima da força natural do sentimento, na medida em que faz da comoção [Ergriffensein] atual do interior uma percepção de si mesmo, um demorar livre junto a si mesmo e dá ao coração, desse modo, igualmente a libertação da pressão advinda da alegria e do sofrimento - o livre soar da alma no campo da música é primeiramente a melodia [...] o compasso, o ritmo, e a harmonia, tomados por si mesmos, são apenas abstrações, que em seu isolamento não possuem nenhuma validade musical, mas apenas por meio da melodia e no seio dela, como momentos e lados da melodia mesma, podem chegar a uma existência verdadeiramente musical” (HEGEL, 2002, p. 315-317). 
cada expressão linguística com um som [Tom] diferente, experimentada tanto por o falante quanto pelo ouvinte, que assim participam duma "[...] linguagem universal das sensações", semelhante ao que acontece com os gestos ${ }^{26}$. É em analogia com esse eixo de comunicação que a música põe em obra uma espécie de "linguagem das afecções" [Sprache der Affekte], que a tradição de Platão em diante costumou denominar "linguagem das paixões". Poderíamos fixar esse topos por meio de textos que iriam da Política de Aristóteles, confiante na potencia educacional da arte dos sons, até a Estética de Lukács:

Nos ritmos e melodias, sobretudo, estão as mimeses mais próximas da natureza real da cólera, da doçura, e também da coragem e da temperança, e de todos os seus contrários, e de outras qualidades morais. Isto os fatos mostram claramente: ao ouvir tais mimeses, a alma muda de estado. E o hábito de se sentir dor ou alegria por tais similitudes está muito próximo daquilo que se sente em face da realidade. ${ }^{27}$

O leitor terá a sensação de não ter passado o tempo, se observar o seguinte trecho de Lukács:

Não havia dúvida para os gregos de que toda a relação humana com a realidade, tanto a científica quanto a artística, se funda numa refiguração da natureza objetiva de tal realidade. [...] Por outro lado, os gregos viram com toda clareza que o objeto mimeticamente reproduzido pela música se distingue qualitativamente dos das demais artes: é a vida interior do homem. ${ }^{28}$

Ainda que alguns proeminentes musicólogos, como Carl Dahlhaus ${ }^{29}$, tenham considerado a teoria das afecções no contexto da música como um elemento contingente, dado que um tema musical pode envolver outros conteúdos diferentes das afecções, seria interessante deter-se no fato de que a "Musik ohne

\footnotetext{
${ }^{26} V d$. AA XXV: 1026-1027; cf. GIORDANETTI, P. 2001, p. 123.

27 ARISTÓTELES, Politica, livro VIII, 1340a, trad. de I. Chasin; Cf. Monteverdi, in: MALIPIERO, 1926-1942, libro VIII, p. 10 (trad. de I. Chasin): "Três são as principais paixões ou afeições da alma. Assim considerei, bem como os melhores filósofos. São elas a ira, a temperança e a humildade ou súplica, como mostra, aliás, a própria natureza da nossa voz, que se faz alta, baixa e mediana; na música, claramente referidas por concitado, mole e temperado. Não pude, porém, encontrar nas composições do passado exemplos do gênero concitado, apenas do mole e temperado, mesmo que o gênero concitado tivesse sido mencionado por Platão no terceiro livro de Retórica [...]; e sabendo ainda que o que move efetivamente nossa alma são os contrários, e que a finalidade da boa música é mover, me dispus com não pouco esforço e estudo a realizá-lo”.
}

${ }^{28}$ LUKÁCS, 1982, trad. de I. Chasin, p. 8.

${ }^{29}$ Vd. (1953), p. 338-347; cf. SCHUBERT, G. (1975), p. 12-25. 
Text" mencionada na $K U^{30}$, na qual alguns interpretadores encontraram o cerne matemático mais autêntico dessa arte, está isenta de tema e justamente por isso não origina afecção nenhuma. Peças desse tipo, resultado da improvisação que ofereceria, por exemplo, uma sessão de jazz, serão vistas com simpatia por aqueles que gostariam de desligar a música em Kant do sentimento de prazer e desprazer, mas então se tornaria indispensável determinar se a carência duma reação emocional não arrebataria essa arte do único veículo de que dispõe e que lhe permite dotar-se de alguma saída, em face da pura transitoriedade. As próprias afecções, verdadeiro ponto de união entre a alma e o corpo e também meio de desencantamento e secularização do mistério que tradicionalmente envolveu esse falso problema ${ }^{31}$, seriam o veículo conector da estrutura matemática duma peça musical com o modo de se sentir o ouvinte a si próprio. Como é bem sabido, Kant diferencia com diligência entre afecções e paixões ${ }^{32}$, como se pode comprovar na Antropologia em sentido pragmático. Os dois termos exemplificam, no campo do sentimento de prazer e desprazer e na faculdade de desejar respectivamente, uma incapacidade para conceder às inclinações o seu peso específico real e não imaginário, mas com a diferença seguinte: as afecções arraigam no estado presente, que confundem com uma totalidade permanente, enquanto as paixões mostram uma maneira de desejar conforme variadas ilusões egoístas, não conforme legítimos princípios racionais. Por isso, as paixões são cânceres e inimigas declaradas da razão, as afecções, porém, uma espécie de embriaguez que estorva transitoriamente o pensamento, são emoções, quer dizer, "[...] comoções passageiras da mente" "33. A obsessão pelo momento presente torna o sujeito prisioneiro duma dor ou duma alegria excessivos que chegam a envolver sem falhas o mundo circundante, que, por obsedantes, podem pôr em causa a vida mesma. O jogo das sensações que a música comporta cumpre a missão de acostumar o corpo a uma oscilação e antagonismo entre as dores e os prazeres, ou

\footnotetext{
${ }^{30} \mathrm{KU}, \mathbb{\int}$ 16, AA 05: 229: “[O]s desenhos à la grecque, a folhagem para molduras ou sobre papel de parede etc., por si não significam nada: não representam nada, nenhum objeto sob um conceito determinado, e são belezas livres. Também se pode contar como da mesma espécie o que na música se denomina fantasias (sem tema), e até toda a música sem texto".

${ }^{31}$ É especialmente proveitoso o artigo de S. Hermann-Sinai (2009), onde lemos, na p. 437: "As afecções, assim, como excitações do ânimo, formam tanto parte da dimensão de atrativo e emoção transitória ou passageira da música como também são transmissoras do tema e, precisamente por isso, a garantia do "movimento continuado e [da] vivificação do ânimo" (KU, AA 05: 329, trad. nossa do alemão). Cf. Hermann-Sinai, 2009, p. 438: "O fato de que um movimento corporal corresponda a uma afecção provocada no ânimo é um ponto decisivo para a interconexão entre música e tempo”.

${ }^{32}$ Encontrar-se-á um exaustivo estudo desses termos, assim como doutros relacionados com o campo semântico da felicidade em Kant, na Tese de Doutorado de Soledad García Ferrer (2011).

${ }^{33}$ ApH, \80, AA 07: 266.
} 
seja, entre a promoção da vida e o impedimento dela ${ }^{34}$. Graças ao gozo musical, as afecções, aprenderão a definhar a sua vivacidade e quebras abruptas dos "diques" anímicos, assim que apagarão os afeitos mais agressivos ${ }^{35}$ :

$[\mathrm{N}]$ o que diz respeito ao sentido vital, não só é movido de um modo indescritivelmente vivo e variado, mas também fortalecido pela música, como um jogo regular de sensações auditivas, que é como uma linguagem de meras sensações (sem nenhum conceito). Os sons aqui são tons, são para o ouvido o que as cores são para a visão: uma comunicação dos sentimentos a distância, num espaço circundante, comunicação a todos os que nele se encontram, e uma fruição social que não é diminuída pelo fato de muitos dela participarem. ${ }^{36}$

A íntima relação entre tom/ som e afecção, segundo Kant, tornaria bem difícil posicioná-lo do lado da Musikwissenschaft. Pelo contrário, uma Musikphysiologie, que teria atraído a leitores como Gilles Deleuze, começa a tomar forma com a ajuda dos raros, porém, densos textos que Kant dedica à música, pois essa arte da qual tratamos, longe de projetar figura [Gestalt] nenhuma de qualquer objeto, aporta câmbios e mudanças apenas referidas ao sujeito ${ }^{37}$, como se estivesse a dar forma a um mundo interior e subjetivo, no lugar de projetar uma realidade exterior. A apresentação da música nos $\iint$ da Crítica do Juízo concentrados na hierarquia entre as belas artes, segundo o peso que o gosto tem nelas, diz-nos que estamos frente a uma arte da comunicação universal que se serve da harmonia e da melodia, em vez de uma forma da linguagem, com o intuito de expressar Ideias estéticas ${ }^{38}$, ou seja, complexos de sentido não conceptuais que "[...] dão muito que pensar"

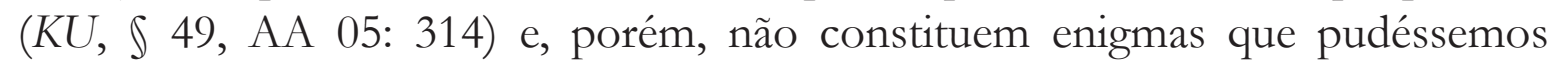
esperar decifrar alguma vez. O característico dessas Ideias é a abertura do campo semântico indeterminado que elas trazem com elas, sempre mais vasto do que a unidade da função conceitual poderia determinar. O que é que a música transmite, segundo esses antecedentes? Se olharmos para a Logik-Philippi (AA 24: 357-358):

A música não fornece absolutamente nenhuns objetos ou descrições dos mesmos. A proporção (Proportion), que em nenhuma espécie de beleza (in keiner Art der Schönheit) é tão exata e tão múltipla como na música, é o que constitui a beleza da mesma.

\footnotetext{
34 ApH, \60, AA 07: 231.

35 ApH, \ 74, AA 07: 252.

36 ApH, \18, AA 07: 155.

${ }^{37}$ Vd. Refl. Anthrop., AA 15: 304-305.

${ }^{38} \mathrm{Vd}$. KU, \57, Obs. I, AA 05: 342: "Uma ideia estética não pode tornar-se um conhecimento porque ela é uma intriç̧ão (da faculdade da imaginação), para a qual jamais pode encontrar-se adequadamente um conceito".
} 
Mesmo que a música não se ocupe da figura das coisas, poderia ser a descida mais profunda que uma arte puder empreender até o mais profundo do ânimo graças a sua capacidade para captar a proporção com a qual decorre a vida. Aqui o problema assenta no estabelecimento do caráter objetivo ou meramente subjetivo dessa proporção ${ }^{39}$. O \ 51 estabelece um desdobro das sensações, especialmente do ouvido e da vista, nas quais deveriam diferenciar-se a mera receptividade passiva duma peculiar afectibilidade [Affektivilität, que Kant enlaça com a reflexão e com a sensibilidade, para captar "diferenças concebíveis" entre qualidades sonoras diferentes:

É digno de nota que estes dois sentidos, com excepção da receptividade para sensações, na medida do que é requerido para obter por intermédio delas conceitos de objetos exteriores, são ainda capazes de uma sensação particular ligada a eles, sobre a qual não se pode decidir com certeza se ela tem por fundamento o sentido ou a reflexão; e que esta afectibilidade não obstante pode por vezes faltar: embora de resto o sentido, no que concerne ao seu uso para o conhecimento dos objectos, não é absolutamente falho, mas até especialmente fino. Isto é, não se pode dizer com certeza se uma cor ou um tom (som) são simplesmente sensações agradáveis, ou se já é em si um jogo belo de sensações e se como tal traz consigo, no julgamento estético, um comprazimento na forma. Se se considera a rapidez das vibrações da luz ou, na segunda espécie, das vibrações do ar, que ultrapassa de longe toda a nossa faculdade de ajuizar imediatamente na percepção a proporção da divisão do tempo por elas, então dever-se-ia acreditar que somente o efeito desses estremecimentos sobre as partes elásticas de nosso corpo é sentido, mas que a divisão do tempo pelos mesmos não é notada e trazida a julgamento, por conseguinte que com cores e tons só se liga o agrado e não a beleza da sua composição. Mas se, contrariamente, se considera, primeiro, o matemático que na música e no seu julgamento se deixa expressar sobre a proporção dessas vibrações, e se ajuíza o contraste das cores, como é justo, segundo a analogia com a última; segundo, se se consultam os exemplos, conquanto raros, de homens que com a melhor vista não puderam distinguir as cores do mundo e com o ouvido mais apurado não puderam distinguir os sons, do mesmo modo como, para aqueles que o podem, a percepção de uma qualidade alterada (não simplesmente do grau de sensação) nas diversas intensidades da escala de cores ou sons, e além disso

39 No Doutor Fausto de Thomas Mann, o palestrante Kretzschmars refere-se à ambiguidade da dimensão sensual e espiritual da música, apresentando a música pura como o verdadeiro fado dela: "Talvez — disse Kretzschmars — seja o mais íntimo desejo da Música não ser ouvida, nem tampouco ser vista ou sentida, e sim, se possível, ser percebida e enxergada unicamente num além dos sentidos e até da alma, numa região espiritualmente pura. [...] Existe [...] um instrumento, isto é, um recurso de realização musical, mediante o qual a música fica audível, mas de um modo meio assensual, quase abstrato e por isso peculiarmente adequado à sua índole espiritual: é o piano, instrumento que não é tal na acepção dos outros, já que lhe falta qualquer caráter específico. Pode-se, na verdade, tocá-lo como solista, à maneira dos demais, e transformá-lo em veículo do virtuosismo, mas isso seria um caso excepcional e, a rigor, um abuso. Tudo considerado, o piano é o direito soberano representante da própria Música, na sua espiritualidade”, p. 61-62. 
o facto que o número das mesmas é determinado para diferenças concebiveis: assim poderíamos ver-nos coagidos a não considerar as sensações de ambos como simples impressão dos sentidos, mas como efeito de um julgamento da forma no jogo de muitas sensações. ${ }^{40}$

Embora alguns homens careçam completamente dessa afectibilidade, como Kant sustenta nesse mesmo $\$ e descreve, na carta a Hellwag, de 3 de janeiro de 1791, a propósito do amigo dele, o comerciante Green, que, ao ler o Essay of Man, de Pope, a única coisa que lamentava era que o texto estivesse escrito em verso, em vez de em prosa, as precavidas indicações de Kant apontam para o fato de que possuir uma capacidade semelhante permite extrair da música uma experiência propriamente estética. Mas isso "[...] não se pode dizer com certeza". Talvez Kant se refira, no trecho referenciado, a uma ilusão de formalidade que a gênese matemática da arte tem em pauta. Pois, se atentarmos para os detalhes, a velocidade do ritmo, em contraste com a estrutura harmônico-melódica duma peça musical, seria um índice suficiente das raízes marcadamente sensíveis dessa arte, na qual podemos reconhecer os três passos duma única aparência:

1. Como jogo de sensações sem conceitos, impõe-se primeiramente a dimensão marcadamente intuitiva do ritmo presente na música.

2. O ritmo combina-se com o eixo harmônico-melódico, que exprime Ideias estéticas.

3. A Ideia estética expressada pelo eixo harmônico-melódico volta sobre o corpo "com força conjugada" [mit vereinigter Kraft].

O seguinte trecho demarca justamente esse itinerário que tem no corpo o alpha e omega do movimento musical: "Na música este jogo vai da sensação do corpo a Ideias estéticas (dos objetos para afectos), e destas então de volta ao corpo, mas com forças conjugadas". ${ }^{41}$

Contamos, portanto, com elementos suficientes para sustentar que, segundo Kant, a música funciona no campo das belas artes como uma aparência dentro do próprio campo das aparências, o que explica a sua instável posição na hierarquia das artes, além de dar licença para ligá-la ao riso despertado pelos gracejos, quer dizer, a "[...] um afecto resultante da súbita transformação em nada de uma tensa expectativa" ${ }^{\text {"42 }}$. Ainda que o riso mantenha uma relação não oscilante com o delir-

\footnotetext{
${ }^{40} \mathrm{KU}, \int 51, \mathrm{AA}$ 05: 324-325.

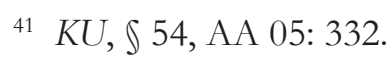

${ }^{42}$ Ibid.
} 
se duma tensa expectativa, como é o caso da música, esta e o riso partilham duma proximidade ao conceito — ou, melhor dito, ao acontecimento — de nada, o qual não é alheio à comunicação entre o jogo sensível, o corpo e o movimento do ânimo. Assim, a música pertence, como outros jogos de implantação social, à vindicação da seriedade do supérfluo num espaço cultural, isto é, à necessidade de reservar um local para um gozo passageiro e aparentemente sem importância nenhuma no seio da mesma cultura. Não parece desprovida de interesse a coincidência entre a aparição do nada, por exemplo, na tabula do nada da primeira Crítica e a demarcação e tomada de consciência dos extremos limites das faculdades do ânimo. De antemão, nesse nada nos jogamos muito desde o ponto de vista do bem-estar anímico, mas seria exagerado pretender que tal jogo possa se tornar um assunto tão sério como o tecido de Ideias estéticas que oferece a poesia ${ }^{43}$. Essa cumplicidade entre música e bagatelle anímico-corporal não nega o enlace entre o som e uma linguagem no sentido mais amplo, assentada num sistema de codificação racional no qual predominam os rastos [Spuren] e signos [Winke] só eloquentes para um ouvinte como o homem:

Os atractivos na natureza bela, que tão freqüentemente são encontrados como que amalgamados com a forma bela, pertencem ou às modificações da luz (na coloração) ou às do som (em tons). Pois estas são as únicas sensações que não permitem simplesmente um sentimento sensorial [Sinnengefüh], mas também reflexão sobre a forma destas modificações dos sentidos, e assim contêm com que uma linguagem que a natureza nos dirige e que parece ter um sentido superior. ${ }^{44}$

Naturalmente, deve salientar-se que a linguagem da qual se fala no trecho pertencente ao $\int$ titulado "Do interesse intelectual" pelo belo da Crítica do Juíro se refere mais a um código produzido no interior do ânimo do espectador do que a um que estivesse objetivamente latente na superfície da natureza e os seus produtos. Mas, os sons emitidos livremente pela natureza pouco têm que ver com a música propriamente dita. Não incomodam como os vizinhos, prisioneiros ou não, dum bairro ou duma cidade pequena como Königsberg. No caso das rêveries du promeneur solitaire, a experiência com as Ideias estéticas aponta para a transição ao simbolismo moral, enquanto o análogo duma linguagem gerada pela música vivifica e move dum modo particularmente variado e íntimo o ânimo. O espectador rousseauniano

\footnotetext{
${ }^{43}$ P. Kerszberg (2003) propõe uma leitura nessa linha da música em Kant. Pode-ser ler especialmente a p. 69 (tradução nossa): "Vista deste ângulo, a música se aproxima talvez mais do que nenhuma outra à satisfação estética maior possível: devido a que o autêntico prazer do sujeito é se iludir sobre o prazer doutros, no momento no qual se impõe completamente a nós pela carência de urbanidade dele, pelo seu poder por ser invasivo demais para o corpo, a música é na beira de se dissolver num quase nada simples aprazimento da ilusão que nunca se toma em serio até ao fundo".

${ }^{44} \mathrm{KU}, \mathbb{\Omega} 42, \mathrm{AA} 05: 302$.
} 
da natureza olha para o céu estrelado sobre mim, todavia o ouvinte da música olha no seu interior, e não precisamente para procurar a voz da lei moral, mas para sentir o ritmo do ânimo, sempre oscilante entre a dor e o prazer.

Ao associar a música mais com o gozo do que com a cultura, Kant convida a observar o fato de que essa arte acorda nos ouvintes um Gedankenspiel, que seria apenas o efeito duma associação mecânica de afecções. Os sons despertam no ânimo Ideias estéticas naturalmente enlaçadas com eles, através da formação dum tema, que marca na peça a afecção dominante, portadora da "unidade qualitativa"45, sem a qual os sons se destruiriam uns a outros. Numa Reflexão, Kant declara que a vivificação do ânimo cumpre melhor o seu escopo quando uma única ideia ou tema percorre o jogo ${ }^{46}$. Os elementos constitutivos dessa unidade são de caráter matemático, pois aqui a matemática não tem parte nenhuma, mas é a asséptica conditio sine qua non do atrativo que a arte produz:

Mas no atractivo e no movimento do ânimo, que a música produz, a matemática não tem certamente a mínima participação; ela é somente a condição indispensável (conditio sine qua non) daquela proporção das impressões, tanto na sua ligação como na sua mudança, pela qual se torna possível compreendê-las e impedir que elas se destruam mutuamente, mas concordem com um movimento contínuo e uma vivificação do ânimo através de afectos consonantes com ele, e assim concordem numa agradável autofruição. ${ }^{47}$

Uma Ideia estética traz consigo, como afirma Claudio La Rocca, “[...] a criação dum campo de possibilidades semânticas [...], quer dizer, duma estrutura de produção de interpretações" ${ }^{48}$, que impede considerá-la como um meio de transmissão dum conteúdo determinado. Os atributos estéticos mantêm sempre alerta o ânimo, ao abri-lo "[à] perspectiva de um campo incalculável de representações afins" "49, que poderíamos descrever como uma espécie de metáfora contínua, que nunca chega a demarcar os seus verdadeiros limites. $\mathrm{Na}$ analítica kantiana do belo, a técnica de natureza alarga consideravelmente o nosso conceito dela ${ }^{50}$, duma maneira completamente enigmática para nós. Frente a ela, a técnica matemática musical faz com que as impressões se interconectem [zusammenfassen] umas com outras e concordem [zusammenstimmen] como afecções consonantes, de

\footnotetext{
${ }^{45} \mathrm{KrV}, \mathrm{B} 114$.

${ }^{46}$ AA 15: 361.

${ }^{47} \mathrm{KU}, \mathbb{\int} 53$, AA 05: 329.

${ }^{48}$ Vd. LA ROCCA (1998).

${ }^{49} \mathrm{KU}, \mathbb{\Omega} 49$, AA 05: 315.

${ }^{50} V d . K U, \S 23$.
} 
sorte que o movimento continuado que essas combinações produzem no ânimo confluem num gozo agradável para o ouvinte. O matemático faz ato de presença na música só para desaparecer na metamorfose dela, numa experiência anímicocorporal. Esta é a posição de P. Kerszberg com respeito à função cumprida pela matemática, no fenômeno do gozo musical, que consideramos bem sugestiva:

Se a matemática desfruta em todo momento duma proximidade intelectual com a música, quando o produto finalizado se oferece à experiência sensível, a matemática desaparece completamente. [...] As regras matemáticas que estão na base de toda composição musical são a condição de possibilidade da música, mas segundo as exigências da crítica, é preciso compreender essa condição de possibilidade sem ela parecer de origem inconsciente (como em Leibniz), pois ela se nega a si própria no momento da impressão vivida. Condição a priori indispensável da música, a matemática não aparece finalmente tão indispensável do que se podia crer, devido ao fato de que o sujeito afetado não a reconhece mais. ${ }^{51}$

Sem dúvida, a matemática faz com que o nosso ânimo jogue de maneira agradável com os sons musicais, mas isso parece responder ao fato de que a Unterbaltung precisa investir diferentes estratégias e trabalho em geral para manter o negócio da vida. A vida apresenta-se sempre em Kant como herdeira e produto de si própria, pois é irredutível a um progresso meramente mecânico, exige sempre algum exercício da liberdade, por mais que este seja ainda tosco e grosseiro, necessitado de gosto: é preciso idear jogos e entretenimentos vários que facilitem a continuidade da vida e garantam a continuada evasão da morte. As proporções e propriedades dos números que tanto estudaram os pitagóricos estão presentes no gozo musical, todavia, Kant se acautela com respeito ao tom enaltecido [vornehmen Ton] no qual os filósofos podem cair inadvertidamente, movidos por um perigoso entusiasmo em face da autonomia da razão na produção de entes geométricos:

Platão, ele próprio mestre nesta ciência - ao deparar com uma tal constituição original das coisas (a qual para ser descoberta implica que possamos afastar toda a experiência) e ao deparar também com a faculdade do ânimo que consiste em poder criar a harmonia dos seres a partir do seu princípio suprasensível (ao que ainda se acrescentam as propriedades dos números com os quais o ânimo joga na música) - entrou num entusiasmo que o elevou, por cima dos conceitos de experiência, a Idéias que lhe pareceram somente explicar-se mediante uma comunidade intelectual com a origem de todos os seres. Não é pois de admirar que ele tenha expulso da sua escola os desconhecedores da arte de medir, na medida em que pensava deduzir da intuição pura que habita

\footnotetext{
${ }^{51}$ Op. cit., p. 66.
} 
o íntimo do espírito humano, aquilo que Anaxágoras deduziu dos objetos da experiência e da respectiva ligação final. Na verdade é na necessidade daquilo que é conforme a fins e constituído como se fosse preparado intencionalmente para o nosso uso, parecendo, no entanto, convir originalmente ao ser das coisas sem se referir a esse uso, que precisamente se encontra a razão da grande admiração pela natureza, não tanto fora de nós quanto na nossa própria razão; pelo que é perdoável que esta admiração, por um mal entendido, se tenha pouco a pouco transformado em entusiasmo. ${ }^{52}$

Longe da ascensão da matemática musical até as Ideias da razão e da dedução da riqueza do mundo da "[...] intuição pura que habita o íntimo do ânimo humano", Kant considera que o intelectualista Platão tinha de receber com urgência quanto aos limites da finalidade objetiva formal alguma decisiva lição do empirista Epicuro, insuperável conhecedor da natureza e das condições da vida. $\mathrm{O}$ primeiro filósofo fez girar a filosofia em torno ao eixo da admiração [Bewunderung] — não uma passageira estupefação [Verwunderung] —, afecção compreensível no processo da pesquisa, mas instrumento ilegítimo de progresso cognoscitivo. Ao juízo de Kant, Epicuro entendeu com toda correção não só a conexão entre toda representação e um estado do ânimo, mas os mecanismos pelos quais se desenvolve o ânimo, quer dizer, o princípio próprio da vida [Lebensprinzį $]^{53}$, que, no caso de não encontrar estímulos ou obstáculos na exterioridade, os procurará em relação com o corpo. Contrariamente à direção assinalada pela tradição dos Schwärmer teoreticistas em filosofia - e dos neoplatônicos na época da Aufklärung, como o cunhado de Goethe, Schlosser, que abusaram do nome de Platão para substituir o trabalho do conceito pelo sentimento do senso comum - a música não deveria levarnos tanto para elevadas esferas — como o tato ou ritmo místico [mystischer Takt $]^{54}$ convida a fazer - , quanto a pesquisar graças a ela o funcionamento da vida em nós ou, se se preferir, as divagações visionárias sobre uma secreta ordem musical do mundo trairiam os benefícios corporais que a música promete. Se tomarmos o segundo caminho, advertiríamos que a transitoriedade das impressões musicais condiz com o antagonismo continuado entre dores e contentamentos, que Kant prezou na obra do conde Verri ${ }^{55}$, sem o qual não seria possível compreender o fenômeno vital. Descobrimos uma segunda valiosa afinidade entre música e vida, no fato de que a primeira se impõe aos sentidos dos outros, também dos que não

\footnotetext{
${ }^{52} \mathrm{KU}, \sqrt{ } 62, \mathrm{AA} 05: 363$.

${ }^{53} \mathrm{KU}$, Allg. Anm., AA 05: 278.

${ }^{54}$ Vd. VT, AA 08: 398. Todas as referências a esse texto de Kant reproduzem a tradução ao português, coordenada pelo prof. V. Rohden, indicada nas referências bibliográficas deste artigo.

${ }^{55} \mathrm{ApH}, \mathbb{S}$ 60, AA 07: 231-232.
} 
formam parte da "sociedade musical", mostrando uma tendência transgressora próxima à pertencente à liberdade, “[...] que pode exceder todo o limite que se queira atribuir" ${ }^{36}$. Esse juízo que põe de sobreaviso frente à incivilidade da música se torna num louvor inequívoco, quando um grupo de indivíduos faz da Tafelmusik um fundo sonoro, que como basso continuo sirva de apoio para conversas variadas e fragmentárias:

[U]ma coisa singular, que deve entreter, somente como um rumor agradável, a disposição dos ânimos à alegria e, sem que alguém conceda à sua composição a mínima atenção, favorece a livre conversação entre um vizinho e outro. ${ }^{57}$

No caso em que estiver em causa um assunto mais sério do entretenimento social - que as "sociedades a-linguísticas" como a própria música, o jogo e a dança, disponibilizam — os tons não seriam o inócuo parerga duma cena social, mas o obstáculo subjetivo dum discurso objetivo, de sorte que a aparição deles produziria incômodo. A música é recomendada como um remédio que cobre aqueles momentos da vida em comum nos quais não há nada que dizer nem que contemplar, com o intuito de nos defender do niilismo que ameaça sem trégua a vida. Se se encontrar no evento social um equilíbrio entre o raciocínio e o gracejo, não será preciso outra fonte do "[...] movimento do diafragma e das entranhas" ${ }^{58}$ distinta das interrupções do primeiro disponibilizadas pelo segundo. Assim, "[...] a música durante um lauto festim de grandes senhores é o disparate mais insípido que a glutonaria já pode inventar" ${ }^{\prime 59}$, pois nesse caso a intervenção musical des-humanizará a sociedade e a afastará das Graças e da humanidade. Segundo Kant, Epicuro tinha mais razão do que Pitágoras e Platão, bem presentes no texto Dum tom enaltecido recentemente percebido em filosofia, ao julgar a natureza da música. O primeiro só cometeu o erro de interpretar erradamente a sua própria hipótese, isto é, que toda representação, seja qual for a origem dela, está ligada subjetivamente ao agrado e à dor, que, no último termo, são sempre corporais, ao afetar o sentimento da vida e modificar conseguintemente o estado do sujeito. A música sabe dessa condição e joga com ela, mas nunca atinge o nível do reconhecimento no conceito, porque o alvo dela é, no fim das contas, o movimento anímico. Dessa maneira, a alma consegue exercer a atividade do médico do corpo, ao alimentar o sentimento de bem-estar dele:

\footnotetext{
${ }^{56} \mathrm{KrV}$, A 317/B 374. No artigo de Buch (1993), esse aspeto da música em Kant é insistentemente posto em destaque.

57 Vd. KU, \44, AA 05: 305; ApH, \88, AA 07: 277-278.

${ }^{58} \mathrm{ApH}, \int 88, \mathrm{AA} \mathrm{07:281.}$

${ }^{59}$ Ibid.
} 
Não é o julgamento da harmonia de sons ou ocorrências espirituosas, que com a sua beleza servem somente de veículo necessário, mas é a função vital promovida no corpo, o afecto, que move as vísceras e o diafragma, numa palavra o sentimento de saúde (que sem aquela ocasião não se deixaria, contrariamente, sentir), que constituem o deleite que se encontra em poder chegar ao corpo também pela alma e utilizar esta como médico daquele. ${ }^{60}$

A matemática será bem-vinda como ocasião do sentimento de saúde, porém, tomá-la excessivamente a sério levaria até o delírio. O próprio Nietzsche reconheceu a justificação dum requisito tradicional para o exercício da filosofia, quer dizer, pôr cera nos ouvidos do futuro filósofo, como lemos no $\ 372$ de $A$ gaia ciência, pois a vida é no fundo música. No vocabulário kantiano: o sentimento vital do ânimo é movido da maneira mais variada e íntima pela música, mas precisamente essa conexão explica a ínfima posição dela na escala artística, porque falamos duma arte que comunica um sentido por meio das Ideias estéticas, mas carece de referência, como tem afirmado J. Stolzenberg ${ }^{61}$. Pascal Quignard, no seu belo livro Butes, medita sobre a enigmática decisão duma personagem secundária das Argonánticas, de Apolodoro de Rodas, homônimo do título da obra, o qual, em contraste com Orfeu, que sai vencedor sobre o canto das sirenas por meio do som emitido pela sua lira, decide cair na tentação representada pelo canto das sirenas, sendo resgatado das olas pela deusa Afrodita. Apolodoro escreve que Butes se levantou do banco onde estava a remar com os companheiros para se lançar ao mar. Quignard reflete da seguinte forma sobre esse acontecimento:

A música não re-presenta nada: re-sente.

É como os nomes quando os nomes ainda não fazem nada diferente de ressonar o afeto. Todo o mundo experimenta esta música da linguagem quando a linguagem não é ainda uma linguagem e não se "tem apoderado pela força" [ebiésato] da alma muito tempo antes de ser apreendida. Estes sonidos — e não os significados deles - sempre nos farão levantar-nos e dirigir-nos àqueles que nos chamam. Os nossos nomes reclamam-nos até à nossa morte. Neste modo a voz antiga dum pássaro com senos de mulher chama a Butes. Chama-o mais do que pelo nome dele: chama-o pelo palpito do coração. Desta maneira, Butes abandona a fila dos remeiros, renuncia à sociedades dos falantes, pula pela borda da nave, arroja-se ao mar. ${ }^{62}$

\footnotetext{
${ }^{60} \mathrm{KU}, \mathbb{\Omega} 54, \mathrm{AA} 05: 332$.

${ }^{61}$ Vd. 2001.

${ }^{62}$ Butes, 2011, p. 17-18; tradução nossa; cf. p. 75-76.
} 
Quignard acrescenta mais à frente que o canto exprime uma saudade existencial, desde que a psyche - a anima das línguas românicas — é uma espécie de tabela na qual se inscrevem as mágoas e sofrimentos, as marcas das vivências. A música teria de ler direitamente o código grafado nessa superfície. Kant partilharia duma descrição semelhante da música? Achamos que a resposta deveria ser positiva, paradoxalmente para a imagem mais ortodoxa desse proverbial inimigo dos cantos. Com efeito, uma primeira consequência duma declaração como esta levaria as considerações musicais de Kant bem além do cenário colocado por Schopenhauer, que, apesar de estabelecer uma relação direita entre música e sentimento, de modo que não faria sentido reduzir à música a uma abstração, recusa sem ambages a esta bela arte a possibilidade de oferecer uma dimensão corporal. A objetividade da vontade atingida pela música chega sem dúvida à essência dela, ao superar o nível das sombras e aparências ${ }^{63}$. A aproximação da música aos movimentos da vontade não teria nada de pessoal ou individual, contudo, serviriam para espelhar, por assim dizer, o sentimento em geral, não sentido, mas afastado de todo sofrimento por meio da mediação estética:

[A] música nunca causa-nos um sofrimento real, mas permanece sempre contente nos seus acordes dolorosos, de maneira que percebemos na sua linguagem a história secreta da nossa vontade [...] Onde quer que, pelo contrário, a nossa própria vontade se veja excitada e atormentada, no plano da realidade com seus horrores, não tratamos com sons e as relações numéricas deles, mas somos nós próprios a corda que vibra ao ser esticada e beliscada. ${ }^{64}$

A música exprimiria os movimentos da vontade na ordem do em$s i$, sem mostrar a reação do corpo na ordem fenomênica das excitações e aspirações daquela. No entanto, a análise de Kant valoriza a influência dos sons musicais sobre o corpo com uma força inaudita em Schopenhauer. Mesmo que reconhecidos especialistas no tema em pauta, como Piero Giordanetti ${ }^{65}$, salientem o fato de que o corpo supõe, no caso de Schopenhauer, o passo dos fenômenos à vontade, enquanto Kant apenas concederia um estatuto empírico a uma arte consistente num jogo agradável das sensações, é preciso reconhecer que a presença do corpo é paradoxalmente mais intensa na consideração kantiana da música do que nas observações do filósofo de Danzig. Enquanto o segundo julga as melodias

\footnotetext{
${ }^{63} \mathrm{Vd}$. SCHOPENHAUER, A. Manuscritos berlineses (tradução nossa): "A música não fala das coisas; fala do bem-estar e da aflição em estado puro (as únicas realidades para a vontade). Por isso, dirige-se ao coração, pois não tem muito que dizer diretamente à cabeça".

${ }^{64}$ SCHOPENHAUER, A. O mundo como vontade e representação, vol. II, \39, p. 435-436 (ed. espanhola, tradução nossa).

${ }^{65}$ Vd. op. cit., p. 231-232.
} 
como expressão não sentimental dos sentimentos, como um reflexo distante da essência da vontade, que nos mantém a uma saudável distância dela, o primeiro abriga sérias dúvidas sobre o fato de que não faça sentido nenhum ouvir uma peça musical sem atentar para a capacidade dela de mover o ânimo e influir sobre o sentimento da vida em nós. Os textos evidenciam que Kant tinha uma visão bastante mais clara do que Schopenhauer sobre a potência fisiológica da música, circunstância que nenhuma conceição idealista dessa arte poderia mascarar:

[A música] não exprime esta ou aquela alegria individual e determinada, esta ou aquela aflição, ou dor, ou espanto, ou júbilo, ou humor, ou serenidade, mas a alegria, a aflição, a dor, o espanto, o júbilo, o humor, a serenidade ela própria, por assim dizer in abstracto, o que neles há de essencial, sem nenhum acessório, portanto também sem os seus motivos. Contudo, nós a compreendemos perfeitamente nesta quintaessência, estampada [...] [E]m toda parte a música exprime somente a quintaessência da vida e de seus processos, nunca estes próprios, cujas diferenças portanto nem sempre influenciam aquelas. Justamente esta generalidade exclusiva sua, concomitante à maior precisão, lhe fornece este alto valor, que possui como panacéia de todos os nossos sofrimentos. ${ }^{66}$

Sobre essa base, poderíamos perguntar quem dos dois pesquisou mais profundamente a íntima ligação entre música e corporalidade ${ }^{67}$. Mas, sublinhada a presença dessa conexão nas tantas vezes consideradas enigmáticas observações kantianas sobre a música, voltemo-nos, na parte conclusiva das nossas considerações, para o motivo inicial que nos conduziu ao estatuto de música entre as belas artes, quer dizer, à presença dum tom, duma Stimmung, como avesso dum entendimento em regime de finitude - não faria sentido uma música para anjos, segundo a terceira Crítica — , radicalmente confrontado pela sua vocação de universalidade ao mystischer Takt no qual os Schwärmer baseiam as posições deles. Os tons emitidos por uma determinada maneira de praticar a filosofia nada teriam que ver com o Tonkunst, mas com a propriedade salientada por Kant das expressões

\footnotetext{
${ }^{66}$ SCHOPENHAUER, A. op. cit., vol. I, \52, trad. nossa, p. 151.

${ }^{67}$ A seguinte observação de Fubini insiste no mesmo ponto: "Como se pode falar da música se, dada a sua posição privilegiada em relação às outras artes, estará, a bem da verdade, além dos conceitos, que alcançam apenas o mundo fenomênico, do qual a música é totalmente independente? Dela só se poderá falar por metáforas, porquanto existe um paralelismo entre música e idéias - ambas objetivaçoes da vontade (FUBINI, Trad. de I. Chasin. 1987, p. 131, grifos nossos); vd. também na p. 133 da mesma obra (grifos nossos): "A música pode colher, exprimir, todas as manifestações da vontade, todas as suas aspirações, satisfações, excitações etc. Nesse sentido, pode exprimir também todos os sentimentos do homem em todas as suas nuances, ou melhor, mais que exprimir pode representar um análogo, porque a música não é fenômeno".
} 
linguísticas para denotar "[...] um afecto do que fala e reciprocamente também o produz no ouvinte, que então inversamente incita também neste a idéia que é expressa na linguagem com tal som" $"$. A fim de descobrirmos o tom adequado a um modo de filosofar, teríamos de mergulhar nas "[...] causas subjetivas no espírito que julga" das diferentes crenças ou considerações de algo como verdadeiro ou espécies de adesão [Fürwahrbalten], segundo as várias traduções disponíveis em língua portuguesa, do nosso entendimento. Essa pesquisa oferecer-nos-á os graus da validade subjetiva das crenças do entendimento, ou seja, a opinião, a fé e a ciência, cujos respectivos tons poderiam ser a persuasão, a conviçãa e a certeza, como lemos na terceira secção do muito musical título "Cânone da razão pura" ", na Metodologia transcendental da primeira Crítica. A eles, o filósofo Schwärmer acrescentará uma espécie de pré-sensação (Abnung; praevisio sensitiva) ${ }^{70}$, isto é, um pressentimento do suprassensível, que substitui o indispensável progresso do entendimento por um salto mortale confinante com o delírio, que crê ouvir o murmúrio [Rauschen] do vestido da deusa sabedoria. Kant objetará com determinação, no texto Dum tom enaltecido... ${ }^{71}$, diante dos supostos benefícios da intuição intelectual grassados pelo Popularphilosoph J. H. Schlosser, o tom orgulhoso dos frutos — das convicções obtidos tão por meio do trabalho paciente do conceito quanto da perseverante interpretação da letra. No final do ano de publicação do escrito anterior, Kant denunciará, noutro opúsculo polêmico, novamente dirigido contra a carta onde Schlosser apresentava uma espécie de prontuário filosófico-pedagógico destinado aos jovens, os prejuízos que as indicações de Schlosser teriam sobre as cabeças dos estudantes:

Seu conselho [tirar do caminho, onde for possível, a Crítica da razão pura] é como a garantia daqueles bons amigos, que propunham às ovelhas: se estas pelo menos quisessem abolir os cães, para viverem com eles como irmãos em contínua paz! - Se o aprendiz der ouvido a este conselho, então ele será um brinquedo na mão do mestre, "para solidificar o seu gosto (como este

\footnotetext{
${ }^{68} \mathrm{KU}, \int 53, \mathrm{AA} 05: 328$.

${ }^{69} \mathrm{KrV}$, A $820 / \mathrm{B} 848$ ss.

${ }^{70}$ VT, AA 08: 397.

${ }^{71}$ Sobre o contexto histórico do escrito de Kant, bastarão só alguns dados aqui, que o leitor poderá completar com ajuda do trabalho de R. Bubner (1995, p. 11-24). J. H. Schlosser traduziu e anotou uma primeira versão alemã das cartas de Platão, nas quais encontrou uma espécie de reconciliação do suposto filósofo idealista com o senso comum. Kant reagiu ao intento de espalhar a ideia da facilidade da filosofia com a publicação do texto mencionado, ao qual respondeu por sua vez Schlosser com o Escrito a um jovem homem que quiser estudar a filosofia crítica. Kant retorquiu a esse escrito com o Anúncio do término próximo de um tratado para a pazperpétua na filosofia (1796), ao qual seguiu uma segunda carta de Schlosser, que nunca recebeu redarguição por parte de Kant. É muito recomendável a introdução da tradutora do texto ao espanhol, C. Gómez Baggethun, que sustenta a presença do registro do tom através da inteira obra crítica de Kant, vd. Logos, vol. 38 (2005), p. 7-12.
} 
diz) por meio dos autores da Antigüidade (na arte da persuasão, por meio de fundamentos subjetivos de aprovação, em vez de um método de convicção por meio de fundamentos objetivos)". Então ele está seguro: aquele [aprendiz] deixar-se-á inculcar a aparência da verdade (verosimilitudo) como probabilidade (probabilitas), e esta, nos juízos que absolutamente podem apenas surgir a priori da razão, com certeza. ${ }^{72}$

Naturalmente, o Popularphilosoph acredita defender legitimamente o recurso ao senso comum no campo dos estudos filosóficos, confiante no fato de poupar por esse meio a tendência dos jovens à revolução e ao descontentamento social, quando em verdade prepara uma morte feliz ou uma eutanásia da filosofia e a completa perda de autoridade dos adultos, face aos irrequietos jovens. Pareceu já um ponto bem relevante para Kant, para o qual é um delito de lesa humanidade tomar o nome do senso comum em vão, quer dizer, corrompê-lo ao abusar do seu nome. Até nos momentos nos quais Kant defende com força "[...] o conhecimento que interessa a todos os homens" "ᄁ3, ele indica inequivocamente que toda orientação sobre o uso do conhecimento aportado naturalmente por esse senso provirá duma cuidadosa análise da razão, que significa o seguinte: há conhecimentos de primeira importância em sentido prático que todos os homens, cultos ou não, possuem, porém, a fim de não estragar tais conhecimentos, os filósofos devem esclarecer analiticamente as fontes que eles têm nas faculdades superiores do ânimo. Em resumo, das recomendações de Schlosser para pensar quase automaticamente só se pode aguardar uma confusão maiúscula dos modos de adesão subjetivamente identificáveis no ânimo, pois "[...] o gênio da arte poética" que se pretende alastrar no campo filosófico é o efeito mais exaltado do entusiasmo que pensadores da Antiguidade, como Platão e Pitágoras, sentiram quanto à racionalidade das figuras geométricas e dos números. A ignorância da profunda diferença metódica que afasta a filosofia da matemática resulta finalmente na inconsciência sobre as fronteiras entre a (má) poesia e o trabalho com os conceitos. Olhemos com maior atenção para essa ilusão sofrida pelos primeiros amantes da sabedoria. Em Dum tom enaltecido..., Kant salienta que Platão percebeu que o nosso entendimento se limitava a ser uma faculdade de conhecer por conceitos, mas ao não ver com claridade a diferença entre filosofia, como conhecimento racional por conceitos, e matemática, capaz de construir a priori os conceitos igualmente racionais dela, teve de fingir um entendimento que se coloca como "[...] fundamento originário de todas as coisas" ${ }^{\prime \prime}$, sede dos arquétipos, isto é, um entendimento divino que teria

\footnotetext{
${ }^{72}$ VNAEF, AA 08: 420.

73 Vd. KrV, A 831/B 859, cf. I secc. da GMS.

${ }^{74}$ VT, AA 08: 391.
} 
introduzido em nós, cópias [ectypa] dessas Ideias primeiras, e como resultado dessa hipótese não produziria nenhum espanto o desejo dos homens de se livrar das pesadas cadeias que os ligaram aos elementos materiais (corpo, copias, fantasias...), que só enturvam o pensamento. Na mesma linha de compreensão, Kant refere-se às fortes restrições, com as quais a música tem bastante a ver, que impediram a Pitágoras descobrir a ordem do suprassensível:

A história conta que a descoberta da relação numérica entre os tons e da lei sem a qual eles unicamente produzem uma música lhe inspirou [a Pitágoras] a idéia: pelo fato que nesse jogo das sensações a matemática (como ciência dos números) contém igualmente o princípio da forma do mesmo (e na verdade, como parece, a priori devido a sua necessidade) — nos habita uma —ainda que somente obscura - intuição de uma natureza que foi ordenada por um entendimento que reina sobre ela segundo equações numéricas; cuja idéia então aplicada aos corpos celestes também produziu a teoria da harmonia das esferas. Ora, nada é mais vivificante dos sentidos do que a música; mas o princípio vivificante no ser humano é a alma; e visto que a música, segundo Pitágoras, repousa simplesmente sobre proporções numéricas percebidas, e (o que é bom notar) aquele princípio vivificante no ser humano, a alma, é ao mesmo um ente livre que se determina a si mesmo: assim a sua própria definição, anima est numerus se ipsum movens, talvez deixe compreender-se e em certa medida justificar-se, contanto que se admita que ele mediante esta faculdade de mover-se por si mesmo quis aludir à sua diferença em relação à matéria, como a que em si mesma carente de vida e somente movível por algo externo, por conseguinte à liberdade. ${ }^{75}$

Pitágoras não estava errado, ao definir a alma como autodeterminação, mas ao enfatizar a identificação entre as condições da vivificação dos sentidos apenas com as proporções musicais e considerar um mistério essa mesma união. Como esteve perto do ponto arquimédico de que a razão precisava, para mobilizar a vontade humana, atribuiu essa força de mobilização erradamente a uma harmonia numérica, em vez de atribuí-la à razão. O preventivo contra essa queda no arcano e no mistério filomatemático é o trabalho ${ }^{76}$, quer dizer, a confiança na forma, que encontra em Aristóteles o melhor representante na altura da filosofia antiga, porque se trata do único proceder para diferenciar convenientemente entre os métodos da razão e demarcar pouco a pouco os limites e funções das representações do ânimo. Os opúsculos do ano 1796 louvam as boas intenções dos filósofos clássicos em face dos mais espertos supostos herdeiros dos pensamentos daqueles. Casos como Platão e Pitágoras confirmam que as boas intenções não bastam, quando se trata de pensar por conceitos, e que não cindir

\footnotetext{
${ }^{75}$ VT, AA 08: 392-393.

${ }^{76}$ VT, AA 08: 393-394.
} 
entre os métodos da matemática e da filosofia produzirá incômodas miragens. Contudo, apesar de ser considerado "[...] embora sem sua culpa, o pai de toda a exaltação em filosofia" "ᄁ7, Platão empregou as Ideias arquetípicas para explicar os fenômenos. Não haveria, portanto, contradição nenhuma no juízo de Kant sobre esse pensador, cujas Ideias ele louva como um magnífico descobrimento:

Platão observou muito bem que a nossa faculdade de conhecimento sente uma necessidade muito mais alta que o soletrar de simples fenômenos pela unidade sintética para os poder ler como experiência, e que a nossa razão se eleva naturalmente a conhecimentos demasiado altos para que qualquer objeto dado pela experiência lhes possa corresponder, mas que, não obstante, têm a sua realidade e não são simples quimeras. ${ }^{78}$

O propósito platônico era digno de encômio, mas o que não podia bastar, como frisamos antes, era um desejo selvagem do suprassensível sem dispor dos instrumentos conceptuais adequados. Uma leitura apressada das suas cartas moveu a indivíduos como Schlosser a afirmar que "[t]oda a filosofia dos seres humanos somente pode desenhar a aurora; o sol tem de ser pressentido"79, mas esse sol será muito provavelmente um sol teatral, um Deus ex machina, que sob a escusa de nos tornar melhores homens obtura o descobrimento da voz da razão em nós, ao qual Kant se refere nos seguintes termos:

Ora, este é o segredo, que somente depois de lento desenvolvimento dos conceitos do entendimento e de princípios cuidadosamente testados, portanto somente mediante trabalho pode ser sentido. -Não é empírico (proposto à razão para solução), mas dado a priori (como efetiva perspiciência dentro de dos limites de nossa razão), e inclusive amplia o conhecimento da razão até o supra-sensível, porém somente em perspetiva prática: não porventura mediante um sentimento que fundamentasse o conhecimento (o conhecimento místico), mas mediante um conhecimento claro que atua sobre o sentimento (o sentimento moral). ${ }^{80}$

O sentimento de respeito origina-se, segundo anuncia o texto, por obra do conceito, ou seja, é originário de uma forma, da qual os escolásticos diziam muito corretamente dat esse rei, que remete à consciência dos limites da razão e nunca desperta suspeitas da tencionar manipular ou pré-fabricar as cabeças,

77 VT, AA 08: 398.

$78 \mathrm{KrV}$, A 314/B 370-371.

79 VT, AA 08: 399.

${ }^{80}$ VT, AA 08: 403. 
conforme a comodidade do Estado, imagem frequente no opúsculo. A posse de um conhecimento semelhante não suscita presunção no sujeito, pelo contrário, propicia o tom da modéstia, da moderação das pretensões, junto com a consciência de dever submeter o conjunto de todas as inclinações ao mandato emitido pela "voz brônzea"81 racional, sem precisar esse mandato prometer vantagem nenhuma, nem ameaçar com sanções no caso de desrespeito. De fato, nenhum castigo poderia endurecer o desprezo que o próprio sujeito sentiria frente a si próprio, se descumprir o que lhe mandar essa voz. Kant chega a dizer que as perguntas que o homem se faz sobre a origem do que escuta "[...] excita a alma toda mediante a admiração pela grandeza e sublimidade de predisposição interior na humanidade e, ao mesmo tempo, pela impenetrabilidade do segredo que ela oculta" ${ }^{82}$ e provoca um espanto provocado por meras Ideias, de modo que faz todo o sentido considerar "[...] que se, para além de doutrinas de moral de escolas e púlpitos, a apresentação deste segredo constituísse ainda uma ocupação frequentemente repetida dos mestres, penetraria a fundo na alma e não careceria tornar os seres humanos moralmente melhores"83. Quem poderia melhorar a quem não se conhece, more socrático, a si próprio? O modus logicus que levará a voz moral em nós a conceitos evidentes terá prioridade em face da representação estética do mandato como a deusa Isis, simplesmente porque a correta compreensão dos conceitos nos protege do mal-entendido das imagens, da mesma maneira que o bom poeta tem de passar antes pela escola da prosa. Sem um trabalho lógico suficiente, um entusiasmo baseado numa consideração exagerada do gênio poético e da matemática presente na música poderá reduzir, em diferentes épocas, as mensagens da razão às declarações dum oráculo, sobre o qual cada um terá direito a se formar a opinião de que gostar, segundo lhe ditar uma inspiração conjuntural. Nada mais longe dos propósitos de liberação da superstição da Aufklärung. Contribuirá para ganhar consciência sobre esses riscos, de acordo com a reflexão kantiana sobre a tonalidade presente na música e na razão, se persuadir, por um lado, de que o filósofo deverá continuar a proteger ou ouvidos dele com cera diante dessa arte, sem renunciar por isso ao agradável sentimento de saúde vital que ela produz com maior força do que nenhuma outra. Por outro, os conflitos atinentes à razão exigem pôr em evidência que um tom acompanha sempre o modo pelo qual pensamos. Um e outro aspecto provam uma dupla receptividade do ânimo humano, segundo esteja o eixo desse processo naquilo que fomenta a atividade vital ou naquilo que nos faz pensar, exercício que

\footnotetext{
${ }^{81}$ VT, AA 08: 402.

${ }^{82}$ VT, AA 08: 402.

${ }^{83}$ VT, AA 08: 403.
} 
nos leva a conhecer uma forma de vida mais elevada e condizente com a autêntica natureza humana.

MADRID, Nuria Sánchez. Philosophy, tone and musical illusion in Kant. From the vivification of mind by sound to the reception of the tone of reason. Trans/Form/Ação, Marília, v. 35, n. 1, p. 47-72, Jan./Abril, 2012.

\begin{abstract}
This article intends, firstly, to enrich the study of the role that the concept of tone plays in Kantian idea of reason, by extending it to the analysis of music as art of sounds, which the Critique of Judgment fulfills. Secondly, it aims to determine the grounds that could explain why the mathematics, due to the specificity of the philosophical method and the physical reception of music, respectively, are itself incapable to express the procedures of reason and of the art of sounds. Finally, it points out a similarity between reason and music concerning their common rejection of succumbing to the Schwärmerei, although the distance which divides them as two contrary ways to exercise and promote the life and its feeling.
\end{abstract}

KEYWORDS: Critique. Reason. Tone. Music. Mathematics. Modes of holding-to-be-true. Feeling of Life.

\title{
REFERÊNCIAS
}

\section{FONTES}

(Traduções utilizadas)

HEGEL, G.F.W. Cursos de estética, vol. III. São Paulo: EDUSP, 2002.

KANT, I. Crítica do Juízo. Trad. de V. Rohden e A. Marques. Lisboa: Imprensa Nacional/ Casa da Moeda, 1992.

- Antropologia de um ponto de vista pragmático. Trad. de C. A. Martins (revisão técnica por M. Suzuki e V. Figueiredo). São Paulo: Iluminuras, 2009.

Que significa orientar-se no pensamento? Trad. de A. Morão. Lisboa: LusoSofia Press, 2005.

Sobre um recentemente enaltecido tom de distinção na Filosofia. Trad. coord. por V. Rohden. Studia Kantiana 10, p. 154-170, 2010.

\section{REFERÊNCIAS SECUNDÁRIAS}

ANDIA, R. Kant e a história da metafísica como idéia filosófica, Marília: UNESP, Campus de Marília, Faculdade de Filosofia e Ciências, 2007. 
BUBNER, R. Platon, Le père de toute exaltation mystique, in: DIXSAUT, M. (Ed.). Contre Platon 2. Renverser Le platonisme. Paris: Vrin, 1995, p. 11-24.

BUCH, E. Critique de la faculté de juger de la musique, IRASM 24/1, p. 59-68, 1993.

DAHLHAUS, C. Zu Kants Musikästhetik. Archiv für Musikwissenschaft 10, p. 338-347, 1953.

FABBRIZI, C. Mente e corpo in Kant, Roma: Aracne, 2008.

FUBINI, E. L'estetica musicale dal settecento a oggi. Torino: Einaudi, 1987.

GARCÍA FERRER, S. La doctrina kantiana de la felicidad: la felicidad como ideal de la imaginación, Madrid: Publicaciones de la UCM, 2011.

GIORDANETTI, P. Kant e la musica. Milano: CUEM, 2001.

HERMANN-SINAI, S. Musik und Zeit bei Kant. Kant-Studien 100/4, p. 427-454, 2009.

KERSZBERG, P. Sur l'impossible critique d'une raison musicale. Kairós, no 21, p. 53-72, 2003.

LA ROCCA, Forme et signe dans l'esthétique de Kant, in: PARRET, H. (Ed.). L'esthétique de Kant. W. de Gruyter, 1998, p. 530-544.

LUKÁCS, G. Estética, Barcelona: Grijalbo, 1982.

MALIPIERO, G.F. Tutte le opere di Claudio Monteverdi, Wien: Universal Edition, 1926/1942.

MANN, T. Doutor Fausto. Trad. H. Caro. Rio de Janeiro: Nova Fronteira, 1999.

QUIGNARD, P. Butes. México: Sexto Piso, 2011.

RIBEIRO DOS SANTOS, L. A Razão Sensivel, Lisboa: Colibri, 1994.

SCHOPENHAUER, A. El mundo como voluntad y representación. Trad. de R. Rodríguez Aramayo. Madrid: Alianza, 2007.

. Manuscritos berlineses. Trad. de R. Rodríguez Aramayo. Valencia: Pre-textos, 1996.

SCHUBERT, G. Zur Musikästhetik in Kant "Kritik der Urteilskraft". Archiv für Musikwissenschaft 32, p. 12-25, 1975.

STOLZENBERG, J. . Musik und Subjektivität oder: Vom Reden über das MusikalischSchöne. Ein Versuch mit Blick auf Kant, in: . K. Cramer zu Ehren, aus Anlass seines 65. Geburtstag. Göttingen: Vandenhoeck \& Ruprecht, 2001, p. 137-153.

Recebido em: 21.11.2011

Aprovado em: 12.12.2011 